\title{
MÚSICOS CEGOS OU CEGOS MÚSICOS: REPRESENTAÇÕES DE COMPENSAÇÃO SENSORIAL NA HISTÓRIA DA ARTE
}

\author{
LUCIA REILY*
}

\begin{abstract}
RESUMO: A representação de músicos cegos foi tema recorrente entre os artistas desde a Antiguidade. O presente estudo descreve historicamente as concepções sobre a figura do músico cego baseado nas obras que atravessam os séculos. A análise da concentração de harpistas na Antiguidade, de tocadores de viola de roda na Idade Média até o Barroco, de violinistas e violonistas entre os séculos XVII e XIX e o aparecimento do acordeão a partir do século XIX permite falar do flutuante papel do músico cego na sociedade. O estudo mostra que na Era Cristã predominava o papel de cego músico, trabalhando na marginalidade e na miséria, onde sua performance musical legitimava a mendicância.
\end{abstract}

Palavras chave: Música. Cegueira. Mundo do trabalho. História da Arte. Representação.

\section{MUSICIANS THAT ARE BLIND OR BLIND MUSICIANS: REPRESENTATIONS OF SENSORY COMPENSATION IN ART HISTORY}

RESUMO: Representations of blind musicians have been a recurring theme among artists since Antiquity. A survey of artworks uncovered nearly 160 portrayals of visual impairment, of which 25 represented blind musicians. This paper presents a historical description of conceptions of blind musicians based on these depictions covering several centuries. The analysis of the concentration of harpists in Antiquity, hurdy-gurdy players from the Middle Ages to the Baroque, violinists and guitar players from the $17^{\text {th }}$ to the $19^{\text {th }}$ century and the emergence of the accordion by the mid $19^{\text {th }}$ century enables us to reflect on the fluctuating role of blind musicians in society, depending on

Doutora em Psicologia e docente da Faculdade de Ciências Médicas (CEPRE) da Universidade Estadual de Campinas (UNICAMP).E-mail: lureily@terra.com.br/lureily@fcm.unicamp.br 
prevailing stereotypes. Analyzing visual cues in artwork shows how musicians that are blind often play the role of blind musicians, working in poverty, on the fringe of society where their musical performance makes begging a legitimate business. The conceit of sensory compensation for loss of sight through heightened hearing is also explored.

Palavras-chave: Music. Blindness. Work. Art history.

\section{Introdução}

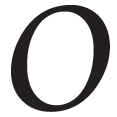

filme documentário A pessoa é para o que nasce, do diretor Roberto Berliner, coloca em evidência uma figura social que faz parte do cenário rural e urbano ocidental há séculos: o músico cego. Maria, Regina e Conceição são três irmãs cegas que se sustentam com esmolas, cantando e tocando ganzá em feiras e portas de igreja no Nordeste. Quando eram meninas, a família de camponeses sem terras acompanhava o pai alcoolista que buscava trabalho temporário nas grandes propriedades rurais. A mãe contribuía fazendo artesanato. Depois que o pai faleceu, a família toda passou a viver com o dinheiro que as irmãs arrecadavam cantando e tocando ganzá. Residindo numa pequena vila em Campina Grande, Paraíba, o primeiro curta-metragem realizado sobre essa história tirou-as do anonimato, e o documentário posterior reflete sobre as conseqüências da fama na vida das três. $\mathrm{O}$ filme retrata uma realidade brasileira, na qual deficiência, miséria e música se entrelaçam.

A referência ao documentário tem a função de introduzir o recorte do presente texto, qual seja, o músico cego, visto à luz de representações de cegos instrumentistas em obras da História da Arte. O título inverte as posiçóes das palavras cego e músico para deixar transparecer desde a abertura do texto a fragilidade do lugar social ocupado pelo cego músico, que carrega historicamente a bagagem do assistencialismo, da marginalidade e da miséria, por um lado, e do mito da superação do infortúnio e da compensação da perda visual pela hipersensibilidade auditiva de outro.

\section{Fundamentação teórica}

As concepções de deficiência são construções sociais, mesmo que, segundo os argumentos de Linton (1998, p. 143), 
(...) o significado geralmente atribuído à deficiência seja de condição pessoal mais do que questão social, de sofrimento individual mais do que uma condição política. Quando indivíduos deficientes fracassam na escola, no trabalho ou no amor, o fracasso é atribuído à deficiência, ela própria vista com um obstáculo ao bom desempenho, ou à fragilidade psicológica do deficiente, ou à sua falta de resiliência, sua incapacidade de "superar" os infortúnios.

Para Linton, as artes têm um papel importante ao "desmontar estereótipos por meio da análise de metáforas, de imagens e de todas as representações de deficiência nas culturas acadêmicas e populares" (idem, ibid., p. 142). Ela explica que a compreensão dos sentidos e das funções das representações simbólicas e metafóricas da deficiência tem o objetivo de subverter o seu poder. "É preciso traçar os padrões de uso de metáforas e dos usos simbólicos da deficiência para determinar onde e como emergem, e como funcionam nos diferentes gêneros artísticos, nas culturas e nos períodos históricos" (idem., ibid., p. 129).

Do ponto de vista de produção de conhecimento, podemos afirmar com razoável grau de segurança que estudos sobre a temática do músico cego são muito mais numerosos que estudos sobre artistas visuais surdos, a despeito do movimento relativamente recente da comunidade surda de desencavar biografias de artistas surdos do passado e de estudar as produções plásticas da comunidade surda como evidências de afirmação e resistência no presente (Lang \& Meath-Lang, 1995). O leitor que queira fazer um inventário de cegos ou deficientes visuais profissionais que se destacaram na música popular brasileira e internacional não terá nenhuma dificuldade em lembrar de referências como Stevie Wonder, Ray Charles, os Cantores de Ébano, Sivuca, Hermeto Pascoal, dentre outros, sem conseguir desempenho equivalente para profissionais surdos no campo das artes visuais. Percebe-se, assim, que a produção científica reflete o que poderíamos denominar de uma sólida tradição cultural, que atravessa espaços e tempos, da possibilidade de desenvolvimento profissional no campo da música para o cego - tradição que não se estende às habilidades artísticas em outras áreas de deficiência.

Pesquisas sobre música e deficiência visual

Os estudos recentes sobre música e cegueira se inserem em diversos campos de conhecimento, incluindo medicina, psicologia, 
antropologia, música e educação musical, entre outros. Na medicina, encontram-se trabalhos que estudam neuroimagens de funções cerebrais de músicos cegos congênitos como evidência da plasticidade cerebral, partindo principalmente das competências de discriminação de tonalidade (ouvido absoluto, ou capacidade musical de reconhecer e identificar notas ou tonalidades ao ouvir um tom ou acorde musical). Hamilton, Pascual-Leone e Schlaug (2004) estudaram 46 cegos que perderam a visão precocemente, dos quais 21 tinham formação musical, comparados a um grupo controle de músicos videntes. A despeito de o treinamento musical dos cegos ter se iniciado mais tardiamente do que a formação musical dos não cegos, 12 sujeitos cegos $(57,1 \%)$ relataram ter ouvido absoluto, quando tal habilidade se encontra em apenas $20 \%$ de músicos videntes, segundo os autores.

Na mesma linha, Ross, Olson e Gore (2003) realizaram um estudo de caso; comparando os resultados de exames de neuroimagem (ressonância magnética funcional) do seu sujeito cego com formação musical e ouvido absoluto aos de cinco músicos videntes com ouvido absoluto, os pesquisadores puderam demonstrar que as mesmas áreas cerebrais no córtex auditivo direito haviam sido ativadas em grau semelhante como resposta ao processamento musical. Os resultados mostraram também ativação adicional no músico cego das regiōes corticais parietais associativas e de regiōes extra-estriados do lobo occipital (ao lado do córtex visual). Os autores consideraram que seu estudo fornece apoio para a explicação da plasticidade cortical como base para habilidades musicais especiais e também justifica a metodologia do estudo de caso para "fenótipos raros".

Amedi et al. (2005) também investigaram, a partir de técnicas avançadas de neuroimagem, as mudanças e adaptaçôes neuroplásticas corticais a partir das exigências e de processamentos sensoriais vividos por sujeitos deficientes visuais, sugerindo que o cérebro responde à cegueira, realocando regiōes que processam informaçôes visuais para outras funções necessárias para as sensaçōes preservadas, como memória, linguagem e habilidade musical.

Um estudo do campo da psicologia investigou os contatos iniciais com a música oferecidos e/ou incentivados na infância. Preocupados com o desenvolvimento das habilidades musicais de crianças cegas, a psicóloga Linda Pring, pesquisadora inglesa conhecida por seus estudos sobre 
as altas habilidades de pessoas do espectro autista, e Adam Ockelford realizaram um levantamento exploratório comparativo (Pring \& Ockelford, 2005) com 32 famílias de crianças com displasia septo-óptica, tendo como grupo controle 32 famílias de crianças sem deficiência visual ou qualquer outro tipo de problema de saúde. O objetivo do estudo foi investigar os interesses e habilidades musicais das crianças, a partir das oportunidades oferecidas a elas de iniciação musical, bem como conhecer os benefícios que a música poderia trazer para o seu desenvolvimento e desempenho escolar. Os resultados levantaram diversas implicações do ponto de vista da educação especial. Segundo os autores, a literatura já vinha indicando que crianças com diagnóstico de displasia septo-óptica apresentam altos níveis de interesse e habilidade musical, mas no estudo desenvolvido, contraditoriamente, as crianças videntes tiveram maior acesso às oportunidades de educação musical oferecidas que seus pares deficientes visuais, enquanto poucas crianças do grupo com displasia septo-óptica puderam desfrutar precocemente da aprendizagem ou terapia musical. Inesperadamente, o fator do resíduo visual parece ter influenciado o desenvolvimento musical mais do que outros fatores, como a compensação sensorial (auditiva).

Há diversos estudos de músicos cegos adultos desenvolvidos no campo da antropologia (especificamente na etnomusicologia), muitos dos quais trabalham em abordagens etnográficas, bastante distintas dos procedimentos empíricos dos estudos da medicina e da psicologia citados acima. Um trabalho interessante foi desenvolvido por Simon Ottenberg (1996) em Serra Leoa, onde conheceu três músicos cegos tocadores de um instrumento chamado kututeng, também denominado em outras regiōes da África de mbira, e conhecido no Ocidente como piano de polegar. Analisando as condições sociais destes homens, verificou que os três eram pobres, solteiros, e não tinham filhos, uma grande desvantagem agregada à condição de cegueira na sociedade Limba, onde o status aumenta conforme o número de filhos. O autor investiga o papel da profissão de músico para esses cegos, e como a história de vida de cada um foi constitutiva do seu estilo distinto de performance, os contextos onde tocavam e a relação da linguagem musical com outros aspectos da cultura Limba. O leitor interessado poderá encontrar outros interessantes trabalhos de etnomusicologia sobre músicos cegos em Kubik (1964), Kidula (2000) e Tsuge (1981). 
Apesar da variedade de objetivos, enfoques, abordagens e metodologias, esses trabalhos iluminam alguns pontos que merecem reflexão. Do ponto de vista médico, as evidências dos estudos neurológicos sugerem que a plasticidade cerebral leva a uma reorganização de funções mentais superiores de modo a valorizar a linguagem, a memória e a musicalidade como modalidades para constituição de sentidos. Para antropólogos o que interessa é o lugar social do músico, enquanto a psicologia se preocupa com os mecanismos de compensação. Assim, profissionais dos campos da medicina, da psicologia e da antropologia interpretam a capacidade musical das pessoas com deficiência visual de diferentes maneiras, mas concordam que a música na vida de uma pessoa com cegueira pode ter uma dimensão especialmente significativa. A implicação óbvia seria que as oportunidades de iniciação musical deveriam ser priorizadas para crianças com cegueira congênita ou que perdem a visão precocemente. No entanto, parece que não é isso que acontece. Os estudos citados mostram que a formação musical de pessoas cegas tem início mais tardio do que ocorre na população no geral, mesmo na Inglaterra, onde a música é disciplina obrigatória para todos nos ensinos fundamental e médio. Algumas hipóteses podem ser levantadas que merecem ser investigadas a fundo para explicar as razões para a demora na iniciação musical de crianças cegas:

- não se oferece uma formação musical o mais cedo possível porque se conta com a propensão inata do cego para a música;

- as famílias com filhos cegos vivem em condições socioeconômicas mais prejudicadas, dificultando a provisão de recursos para compra ou aluguel de instrumento e pagamento de professores de música;

- poucos professores de música se sentem habilitados para ensinar alunos com deficiência visual;

- a música não é entendida como uma profissão, e sim como um meio de sensibilizar o público para jogar moedas num chapéu ou caneca; para isso, não é preciso estudar música, basta tocar alguma coisa.

Fundamentada em autores da sociologia da arte, como Bourdieu e Darbel (2003), Brown (2007) traz uma reflexão que contribui para elucidar a posição ambivalente do músico cego. Para esta estudiosa dos 
músicos do norte da Índia, no império Mughal (c. 1658 a 1858), os músicos profissionais da maioria das sociedades possuem um status limítrofe. Considera que a ocupação do músico é ao mesmo tempo uma profissão de serviço e de trabalho cultural. O capital cultural proveniente do produto de sua labuta - sua música - permite aos músicos atravessar para espaços de status mais elevados, para se relacionarem em pé de igualdade com seus patronos, e no momento da performance, é possível exercer poder sobre eles. Para aqueles que mais se destacam, essa mudança de lugar social poderá se tornar permanente. Mas a autora alerta que, em muitas sociedades, não interessa aos patronos permitir aos músicos escapar de seu lugar nas bordas e, para mantê-los subservientes, são capazes de utilizar sanções sociais.

A discussão desenvolvida por Brown sugere que, de um lado, os músicos cegos ficam muito mais vulneráveis às sanções sociais que os músicos videntes, encontrando ainda mais dificuldade para conseguir que o seu capital cultural seja reconhecido como um bem simbólico, e de outro, ao menos nas sociedades que professam o cristianismo, a moeda de troca talvez não seja propriamente a música. A performance musical do deficiente oferece ao público a oportunidade de admirar a espantosa capacidade que o cego tem de superar a sua condição, de compensar o seu defeito, enquanto se sente satisfeito por fazer o bem, dando uma "ajudinha"; assim redime sua própria culpa e vacina-se contra a possibilidade de vir a se tornar deficiente (Gilman, 1994).

\section{Retratos de cegueira}

O presente estudo é um desdobramento de um levantamento imagético desenvolvido a partir da pesquisa "Retratos de deficiência e doença mental: intersecções da educação especial e da história da arte”, que teve como objetivo mapear retratos de deficiência e doença mental na história da arte, para investigar raízes do preconceito em obras de arte ocidental. Partiu-se da premissa de Gilman (1994) de que os artistas expressam estereótipos coletivos vigentes na sociedade, mas que estas imagens consolidam as atitudes perante a deficiência, estabelecendo um movimento iconográfico de escritura e leitura de sentidos visuais.

Ao analisar as representações da deficiência visual em obras da história da arte, o pesquisador logo se dá conta do grande desafio que 
o artista enfrenta para mostrar que o seu tema é a cegueira, já que o "não ver" é ausência de função, uma abstração, não um traço físico definido. O desenhista ou pintor, então, lançará mão de alguns sinais constituídos por artistas que estabelecem uma tradição iconográfica para auxiliar o público na leitura da sua mensagem. Em se tratando de deficiência física, há muitos sinais pictóricos disponíveis ao artista. Cadeiras de rodas, muletas, tutores ou suportes amarrados às pernas, perna de pau, membros mecânicos, próteses, bengalas, membros ausentes, deformidades e outros elementos são fáceis de identificar.

Para representar a cegueira numa imagem de natureza visual, no entanto, a dificuldade é maior. Os olhos são pequenos, meros detalhes numa pintura; um olhar ausente, vago, pode ser equivocadamente interpretado como alguém com pensamento distante, em vez de alguém que não enxerga. Elencamos diversas soluções utilizadas pelos artistas nos seus retratos de cegos que foram constituindo uma tradição iconográfica da cegueira, de tal forma que o público fosse aprendendo a ler esses detalhes em desenhos, pinturas, gravuras e esculturas.

Para começar, o título da obra pode conter referência explícita à cegueira ou pistas a serem confirmadas na própria imagem. Algumas obras não figurativas modernas e contemporâneas do século XX, como a pintura de Max Ernst "Nadador cego" ou a escultura de Louise Bourgeois "Um cego guiando o outro", sem a menção de cegueira no título, seria impossível ao público, tanto aos leigos quanto aos especialistas em arte, identificar a representação da deficiência visual.

Muitos artistas contam com os subtextos para auxiliar os leitores da imagem na interpretação dos sentidos. Quando o público sabe da cegueira de alguns personagens mitológicos, de figuras bíblicas e de personagens históricos, este conhecimento prévio servirá de suporte para a interpretação da obra. Os artistas medievais, preocupados que foram com a leitura das imagens que ilustravam (iluminavam) textos religiosos de toda natureza, mostraram-se muito inventivos na criação de pistas visuais para a leitura das imagens, as quais foram revisitadas por muitos artistas ocidentais que se seguiram. Dessa forma, colaboraram com a construção de uma iconografia sobre a cegueira.

No decorrer da história da arte, vemos a cegueira representada figurativamente por meio dos seguintes elementos: 
- olhos fechados/abertos após a cura; olhos esbranquiçados, órbita vazia, olhos feridos ou disformes, olhos de vidro, direção do olhar assimétrico, olhar ausente, vazio;

- uso de vendas, de óculos escuros, de lentes grossas, de recursos ópticos;

- indicação pelo apontar, mostrando ou tocando os olhos;

- pistas posturais, como a cabeça erguida, braços estendidos diante do corpo, mão aberta varrendo o ar, passo inseguro, com um pé à frente, mapeando o terreno a procura de obstáculos ou buracos;

- corpo prostrado, figura deitada na cama, figura sentada desocupada ao lado de outra pessoa trabalhando a seu lado;

- presença de bengala, vara ou instrumento musical;

- tamanho das mãos proporcionalmente aumentadas; mãos tocando, sentindo algo;

- presença de auxiliar, guia, criança ou cachorro levando o cego;

- presença de tigela ou chapéu para o público colocar moedas.

Analisando as obras no seu conjunto, constataram-se raros exemplos de deficientes mostrados como pessoas capazes de fazer parte do mundo do trabalho. Algumas exceções merecem menção. Artistas com deficiência pintaram seus auto-retratos (Francisco de Goya - surdo; Henri de Toulouse-Lautrec - deficiente físico; Frida Kahlo - deficiente física) e pintaram representaçôes idealizadas de personagens históricos que tiveram papel destacado na sociedade. Retratos do filósofo Homero (cego), do general romano Belisário (cego) e do poeta inglês Milton (cego) são temas recorrentes. Também há diversas representaçôes de militares incapacitados, que se tornaram deficientes por mutilação no campo de batalha, no entanto estes geralmente aparecem como mendicantes, aposentados ou inúteis.

\section{Cegos músicos}

As representações de músicos cegos na história da arte atravessam tempos e espaços. Em nosso levantamento, encontramos 25 obras 
sobre tal temática. $\mathrm{Na}$ impossibilidade de reproduzi-las, um breve sumário poderá auxiliar o leitor a se situar em meio ao conjunto de representações.

São vários os instrumentos representados, com algumas menções nos títulos sobre o canto como acompanhamento. Nos tempos mais distantes, na arte do Egito e da Mesopotâmia, a harpa é a preferência, enquanto a viola de roda (hurdy-gurdy), instrumento de corda que soa como uma gaita de fole e funciona girando uma manivela, é comum nas obras da Idade Média até o Barroco. Surgem no século XVII cegos tocando instrumentos de corda (violão, violino e viola da gamba); o acordeão faz sua primeira aparição nas mãos de uma cega música no Romantismo. Já no século Xx, vemos representações de blues e jazz, com músicos negros tocando pandeiro e violão na pintura de William Johnson e piano, sax, trompete e bandolim em "Jazz Wall", de Marisol.

A maioria das obras retrata cegos solitários, mas alguns trazem uma criança como acompanhante, cuja função é guiar o deficiente ou coletar moedas num chapéu ou tigela. Também há cães em cena, com funções parecidas às das crianças, em desenhos como a iluminura medieval e a gravura em metal de Rembrandt. Os conjuntos apresentam diversas composições: grupos de músicos, dentre os quais um instrumentista é cego; duplas de cegos; grupos em que todos os integrantes são cegos.

O público é retratado em poucos trabalhos. A obra mais conhecida, "O violonista cego" de Goya (Museo del Prado em Madri), traz uma cena bucólica onde o músico cego é o centro das atenções, alegrando o convívio social do grupo que se aproximou para ouvi-lo. Outros trabalhos europeus trazem o músico como "vendedor de canções", tocando para um público restrito em residências humildes. Nos séculos XVII, XVIII e XIX, o violino, a viola e o violão são os instrumentos preferidos pelos cegos ambulantes, tocados muitas vezes a céu aberto ou em espaços domésticos. É interessante notar que as representações do final do século XX mostram que os instrumentos mudaram, a mendicância ficou menos escancarada, mas o músico cego ainda é representado nas bordas da sociedade.

Analisando os trabalhos numa dimensão cronológica, pudemos perceber alguns fatores de relevância para a nossa discussão, principalmente sobre as representações do músico cego em condições sociais diversas. 


\section{Harpistas cegos retratados na Arte Antiga}

$\mathrm{Na}$ Arte Antiga egípcia, assíria e mesopotâmica, as representações encontradas de cegos tocando harpa aparecem predominantemente na arte mural, como detalhes em baixo-relevo em pedra decorando construções públicas. Como exceção, temos uma placa em terracota da Mesopotâmia que sobreviveu apesar de sua fragilidade (hoje no British Museum) e um harpista num mural pintado no interior do túmulo do escriba e sacerdote Nakht, no Cemitério dos Nobres em Tebas, no Egito. A identificação da cegueira é difícil na maior parte das imagens antigas, devido ao tamanho das reproduções digitais, porque o detalhe disponível on-line não permite ver outras pessoas na cena que serviriam de comparação. Sabemos que os harpistas são cegos pela descrição fornecida nas fontes de busca (como o Art Resource/New York) e em obras de referência descritivas das obras em questão.

O harpista cego do mural egípcio faz parte de uma cena festiva onde moças dançam, enquanto um banquete é preparado. Os egípcios acreditavam que a morte seria uma etapa alterada da vida, daí a necessidade de prover tudo que fosse necessário para o conforto e bem-estar do morto durante toda a eternidade. Representaçóes em tamanho menor e imagens bastavam para cumprir tal função; não era preciso sepultar objetos e pessoas reais dentro das tumbas, segundo Brock (2006). A presença de um harpista cego pintado na parede de calcário da tumba de Nakht sugere que um músico cego trabalhava na corte deste nobre. Ao incluir sua imagem no mural, pretendia-se que a sonoridade da harpa o acompanhasse na nova etapa de sua viagem após a morte.

Já o harpista esculpido no baixo-relevo fixado nas paredes do Palácio de Nineva nos jardins de Senaqueribe provavelmente está mais relacionado ao gênero apoteótico militar do que ao ritualístico religioso. Esse músico faz parte do friso decorativo que cobria boa parte das paredes internas e externas do palácio. Senaqueribe mandou esculpir dois tipos de inscriçóes para enfeitar o edifício: 1) desenhos decorativos de procissóes cuja intenção era enaltecer os seus feitos e 2) composiçôes narrativas, sobre as várias campanhas militares do rei.

Diferentemente do harpista egípcio, que trabalha ajoelhado, em posição estável, a figura assíria é ambulante. Produz música enquanto marcha. É interessante notar que, em muitas obras encontradas na Era 
Cristã, o cego músico aparecerá tocando de pé ou como ambulante, portando seu instrumento consigo, o que facilita o encontro de novos públicos de um lado, mas, de outro, exige um guia, pois ele não pode usar uma bengala se caminha enquanto toca seu instrumento.

\section{Figura 1}

Anônimo: Um harpista nos jardins de Senaqueribe Baixo relevo em pedra do palácio de Nínive, século VII a.C. Neoassírio

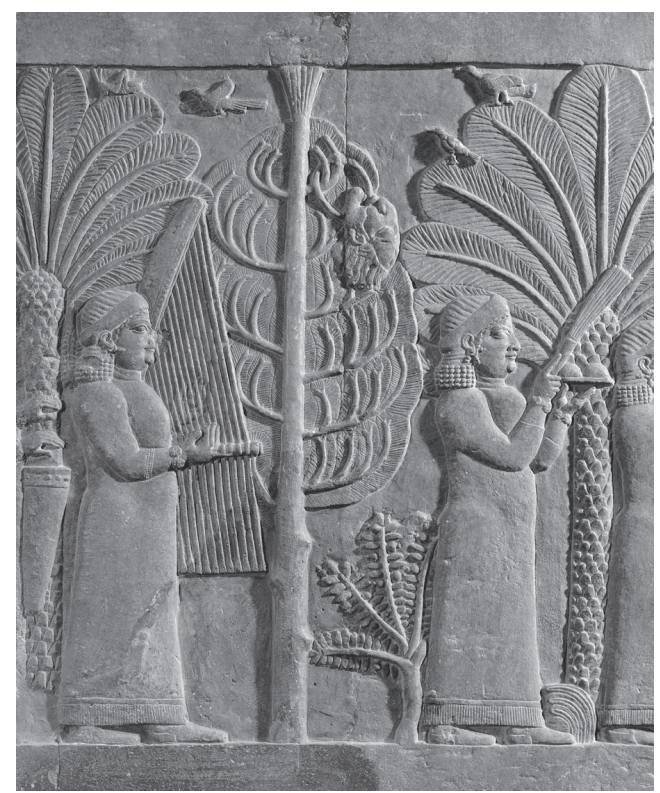

Fonte: British Museum, Londres, Reino Unido).

Foto: Erich Lessing/Art Resource, NY

\section{Cegos instrumentistas e a viola de roda}

$\mathrm{Na}$ Idade Média, aparece um novo instrumento que não se ouve mais na atualidade: a viola de roda, ou hurdy-gurdy em inglês. Segundo Green (1995), uma certa confusão decorre do fato de que o mesmo termo hurdy-gurdy se refere a dois instrumentos: "primeiro existe o órgão mecânico, que tem um mecanismo muito parecido com a pianola, 
e era tocado no começo do século por imigrantes que pediam esmolas com seus macacos e canecas de latão nas esquinas das cidades americanas". No Brasil, conhecemos este instrumento como o realejo; os franceses o chamam de orgue de barbarie.

Menos conhecido é um instrumento cujo som é produzido por uma roda coberta de resina que esfrega várias cordas, assim como o arco de um instrumento de cordas. A roda gira por meio de uma manivela. Algumas cordas têm uma função melódica e outras fazem a base, dando ao instrumento uma sonoridade parecida com uma gaita de fole. (Green, op. cit., p. 1)

$\mathrm{Na}$ França, este instrumento é denominado de vielle; em português o termo usado é viola de roda. $\mathrm{O}$ instrumentista aprendia a controlar o vibrato da roda nas cordas para criar uma sonoridade expressiva que lembrava o canto. Não é possível variar a pressão da roda sobre as cordas, como se faz passando o arco num instrumento de cordas como o violino ou o violoncelo, de modo que a expressividade é conseguida alterando a velocidade com que a manivela é virada (Green, 1995).

\section{Figura 2}

Jehan de Grise e ateliê, Bas-de-page - Músicos (e músico cego com seu cachorro e tigela de esmolas toca uma viola de roda) - 1338-1344 dC

Bodleian MS 264 part I fol. 180v. Iluminura do "Romance de Alexandre" em pergaminho

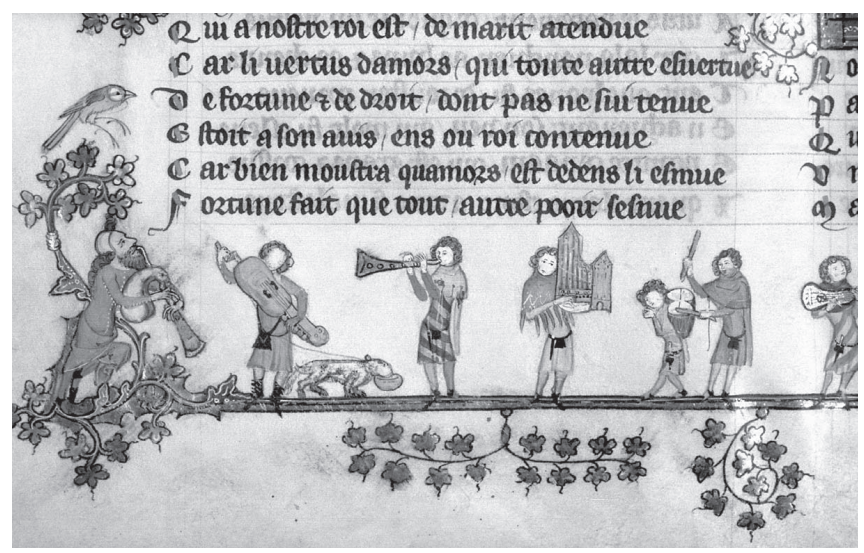

Fonte: Bodleian Library, Oxford, Reino Unido. 
$\mathrm{Na}$ iluminura de bas-de-page do manuscrito "Romance de Alexandre", do acervo do Bodleian Library, o cego tocador de viola de roda faz parte de um grupo de músicos de rua. A cegueira é indicada pela ausência de olhos e pelo cachorro que leva sua tigela para juntar as esmolas.

Segundo Green (1995), nenhum instrumento musical passou por uma perda de status tão marcante quanto a viola de roda. No século XI na Alemanha, era usada em música sacra. No século seguinte, o instrumento migrou para a corte, onde fez sucesso entre os nobres. Mas daí em diante, começou a perder prestígio. "Já no século XIV, era associada às classes baixas e no século XV havia se associado aos mendigos cegos" (idem, ibid., p. 1). Segundo o autor, como a cegueira era vista com repulsa, por ser concebida como manifestação física resultante de uma cegueira moral, a viola de roda tornou-se um instrumento desprezado que serviria apenas para os mendigos deficientes.

\section{Figura 3}

Francisco Herrera o Velho (c.1576-1656) - Cego tocador de viola de roda, 1640.

Óleo sobre tela, $71,5 \times 92 \mathrm{~cm}$

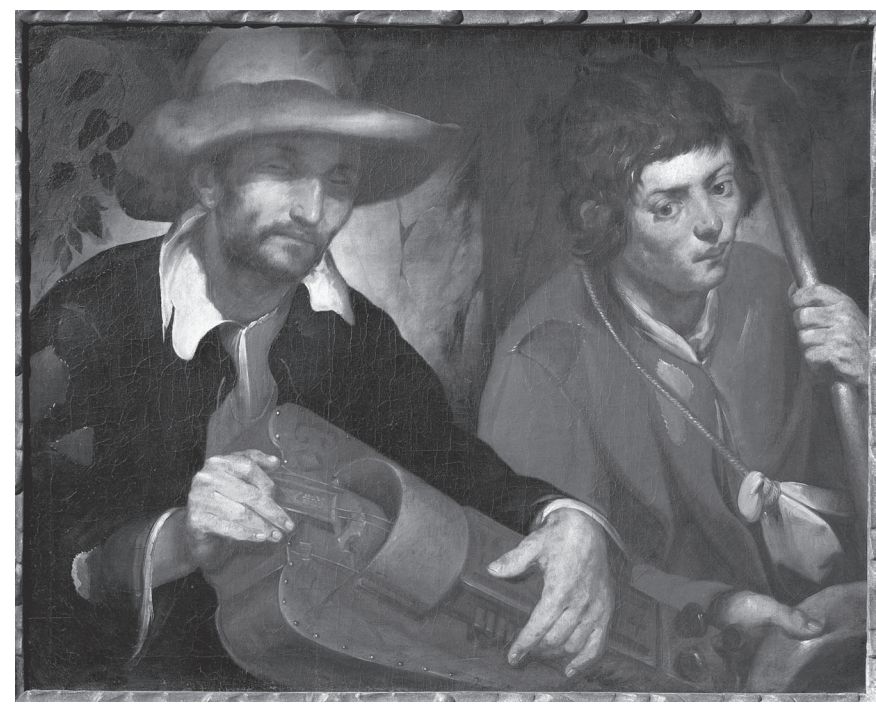

Fonte: Kunsthistorisches Museum, Viena, Áustria. Foto: Erich Lessing/Art Resource, NY 
A obra de Herrera expressa claramente esta situação. O cego músico maltrapilho está acompanhado de um rapaz que segura sua bengala e estende o chapéu para coletar as esmolas. Os semblantes de ambos estão tristes e desesperançosos, coerentes com as tonalidades escuras, com predomínio de marrom. O músico está tocando ou está em compasso de espera? Nada no quadro sugere o clima de alegria que a música costuma despertar nas pessoas.

\section{Sentidos expressos nos retratos de músicos cegos}

Os temas miséria e mendicância são constantes nos retratos dos cegos músicos da Era Cristã. Rembrandt van Rijn, Pablo Picasso, Georges de La Tour e vários outros utilizam a coloração sombria, a composição de figura em primeiro plano, com a postura de ombros caídos, a expressão triste do rosto, para falar da condição precária desta figura urbana, cujo trabalho é ao mesmo tempo ganha-pão e manifestação de súplica.

A dualidade esperança desesperança também é expressa simbolicamente, principalmente a partir dos artistas do Romantismo. John Everett Millais, pintor romântico inglês, desenvolveu diversos estudos sobre a menina cega nos quais a temática em questão ganha uma dimensão moralizante, de lição de vida.

No famoso quadro de Millais, a jovem cega está com sua sanfona no colo; a cabeça erguida permite que seu rosto tranqüilo seja iluminado pelo sol que saiu por detrás das nuvens, agora que a chuva passou. A pista é o arco-íris no alto do quadro sobre um céu ainda escurecido pela chuva que agora se distancia. A criança que acompanha a cega se volta para olhar para este sinal de esperança. Mas a cega tem outros meios de saber que o sol saiu, que a vida pode ser boa, pois ela sente o calor no próprio rosto.

Abordando a cegueira como uma situação possível de ser superada, Millais inclui elementos para apresentar a idéia da compensação pela perda da visão: a luz e o calor do sol que tocam o rosto da jovem, o signo da capacidade musical indicado pela presença da sanfona. Certamente o artista não fala só da condição de deficiência. Como pintor do Romantismo, sua mensagem tem um teor mais abrangente, e pretende atingir a sociedade de maneira geral. Millais utiliza a cegueira como metáfora para falar de quaisquer infortúnios e da possibilidade de superação, da chegada de tempos melhores. 


\section{Figura 4}

John Everett Millais (1829-1896) - Menina cega, 1856

Óleo sobre tela, 82,5 x $62,2 \mathrm{~cm}$

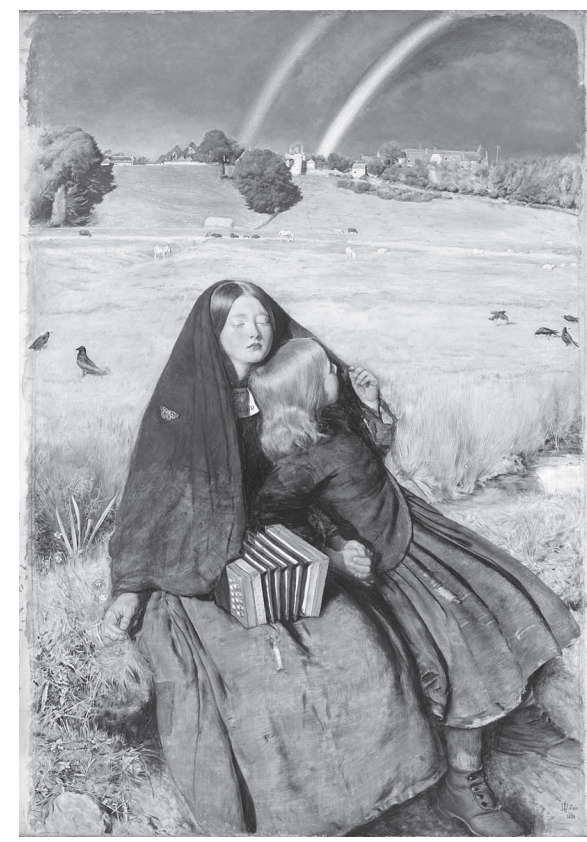

Fonte: Birmingham Museums \& Art Gallery, Birmingham, Reino Unido

Refletindo sobre esta mesma temática a partir da figura do músico que não pode ver, George Watts trabalha explicitamente com o revés deste tema. Numa pintura sombria denominada de "Esperança", Watts coloca uma figura feminina de olhos vendados, com uma túnica que revela sua condição social desfavorecida, sobre um globo. Sua harpa não pode soar, porque as cordas romperam. É interessante que num mesmo signo, música e cegueira se associam para abordar esperança ou desesperança. Ambos os quadros foram favoritos da sociedade inglesa quando foram expostos no século XIX.

Desenvolver-se como músico afirma a validade do conceito de compensação da perda visual. Esta é a idéia que alinhava todas as obras 
encontradas que abordam a temática do músico cego: quem não enxerga, verá com outros olhos, os olhos de dentro. Para quem perdeu a visão, a audição será seu caminho de luz.

Ninguém acentua essa representação da cegueira com maior eloqüência que Ben Shahn. A sonoridade da música produzida pelos deficientes representados não pode ser traduzida pelos elementos de linguagem visual e composição disponíveis para os artistas plásticos, então outros recursos são criados para falar das outras dimensões sensíveis do homem.

\section{Figura 5}

Shahn, Ben (1898-1969) - O cantor cego, 1945

Têmpera, 64,7 x 97,1 cm, Coleção Particular

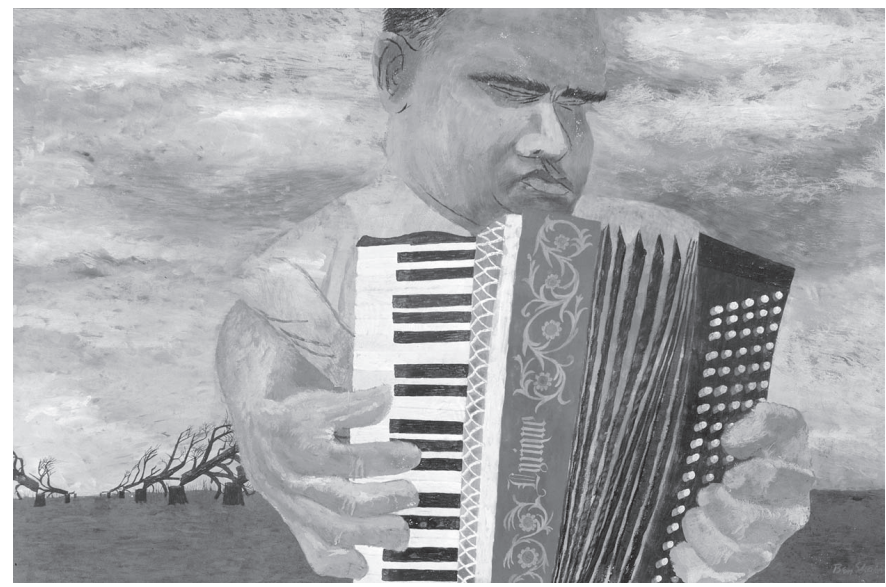

Foto: Scala/Art Resource, NY; Licenciado por AUTVIS, Brasil, 2008. (C) VAGA, NY

Ben Shahn, pintor e litogravurista de família imigrante lituana que pintou nos Estados Unidos em meados do século XX, transmite a idéia da compensação ao exagerar a dimensão das mãos do cantor cego. Os dedos sobre o teclado e os conjuntos de botôes de seu acordeão revelam a sua familiaridade com o instrumento e o seu domínio técnico. Contrasta com a expressão de competência o fundo da pintura, onde árvores mortas e secas no horizonte a distância recolocam a idéia de penúria. Os múltiplos sentidos da figura da sequidão permitem ao intérprete pensar 
nos olhos que secaram ou na sociedade que relega às margens aqueles que perderam alguma função, mesmo quando demonstram que são capazes. Conhecendo Ben Shahn, militante, comunista "de carteirinha", que utilizou sua arte para realizar críticas sociais ao capitalismo, defensor da classe trabalhadora, dos pobres, negros e excluídos, desiludido com o sonho americano, nossa aposta é que ele utiliza a terra desgastada do fundo para enfatizar a idéia do cego músico cantando nas bordas da sociedade. Como explica Dijkstra (2003, p. 117):

A obra dos expressionistas americanos é impulsionada pela compaixão e empatia, pelo respeito pela dignidade dos derrotados, por uma compreensão de que as experiências pessoais, mesmo daqueles entre nós que são menos favorecidos, ajudam a definir as verdadeiras qualidades da sociedade na qual vivemos.

\section{Figura 6}

William H. Johnson (1901-1970) - Músicos cegos (ou "Músicos de Rua"), circa 1940-45.

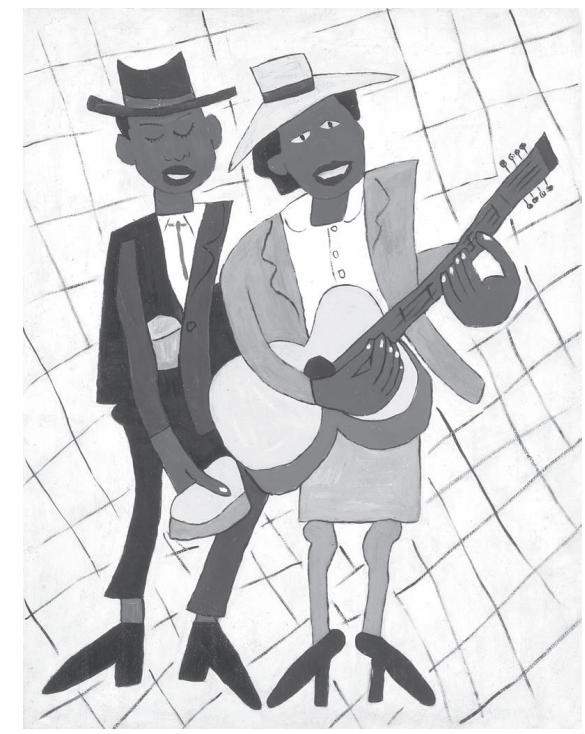

Foto: Smithsonian American Art Museum, Washington, DC/ Art Resource, NY. (C) Copyright 


\section{Figura 7}

Marisol (Marisol Escobar) - Parede de Jazz, c. 1962

Papel, tinta e objetos encontrados em madeira, $241.3 \times 271.8 \times 35.6 \mathrm{~cm}$ Coleção Museum of Contemporary Art, Chicago, doação parcial de Ruth Horwich

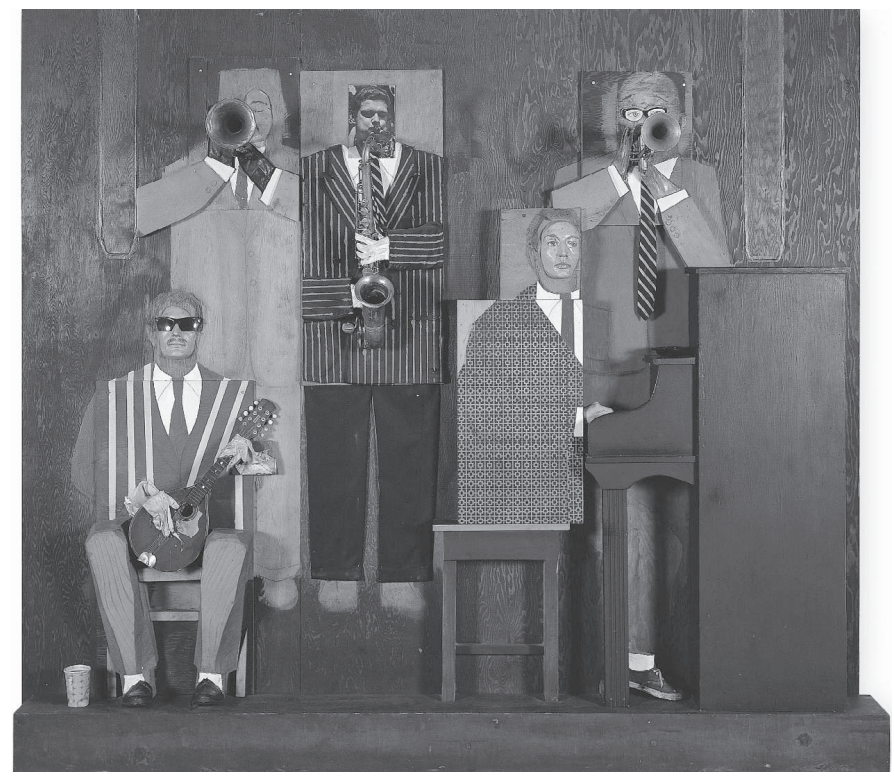

Foto: Museum of Contemporary Art, Chicago; Licenciado por AUTVIS, Brasil, 2008 (C) VAGA, NY

As duas últimas obras comentadas também apresentam o músico cego na marginalidade, mas os elementos tristeza e dependência se dissipam em ambos os trabalhos - uma pintura e uma escultura. Coincidentemente, o gênero representado nessas obras é da família do blues e do jazz. Músicos - cegos - negros - pobres. Por todas essas condições, esses músicos são vulneráveis ainda, mas de certa forma tiveram êxito na travessia para espaços de status mais elevado, ao menos durante a performance, conforme Brown (2007). Não se trata de uma conquista individual; estes músicos fazem parte de uma minoria de resistência negra do sul dos Estados Unidos que conseguiu o reconhecimento do valor do seu "capital cultural" na sociedade de brancos que os perseguiu e injustiçou. 
Pela mobilização política e social e pela qualidade musical, a vocalização provocativa e a característica fugidia das improvisações que escapavam a qualquer dominação por partitura - assim sobreviveram os músicos, assim mudaram a história da música popular americana, com repercussões internacionais. A este contexto se somaram os cegos músicos, que ali puderam mudar de papel. Os músicos de Marisol tocam num bar e têm até um piano!

Para finalizar, um alerta. Se este artigo termina em "tom maior", mostrando que as condições de trabalho dos músicos cegos representadas por artistas visuais da Era Cristã evoluíram, não nos deixemos enganar. As concepções de dependência, incapacidade e supercompensação pela perda da visão ainda permeiam as representações sociais da deficiência visual. As precárias condições de vida continuam prejudicando as possibilidades de acesso de crianças cegas à educação em geral e à educação musical em específico, perpetuando a mendicância de um lado e o assistencialismo do outro - lugares sociais que coloriram a visão da sociedade e dos artistas plásticos sobre a figura do cego músico durante toda a Era Cristã.

Recebido em março de 2008 e aprovado em julho de 2008.

\section{Referências}

A PESSOA é para o que nasce. Direção Roberto Berliner. São Paulo: Estúdio Europa, 2006. 1 DVD (84 min.): DVD, son., color.

AMEDI, A.; MERABET, L.B.; BERMPOHL, F.; PASCUAL-LEONE, A. The occipital cortex in the blind. Lessons about plasticity and vision. Current Directions in Psychological Science, Washington, DC, v. 14, n. 6, p. 306-311, 2005.

BOURDIEU, P.; DARBEL, A. O amor pela arte: os museus de arte na Europa e seu público. Trad. de Guilherme João de Freitas Teixeira. São Paulo: EDUSP; ZOUK, 2003.

BROCK, J.F. Four surveyors of the gods: in the XVIII dynasty-New Kingdom c. 1400 b.C. In: American Congress on Surveying and Mapping, 2006, Orlando Florida, EUA. Annals of the 2006 ACMS Conference, Orlando, Florida, Professional Surveyor Magazine 2006. p. 1-16. 
BROWN, K.B. The social liminality of musicians: case studies from Mughal India and beyond. Twentieth-Century Music, Cambridge, v. 3, n. 1, p. 13-49, 2007.

DIJKSTRA, B. American expressionism: art and social change 19201950. New York: Harry N. Abrams, 2003.

GILMAN, S.L. Disease and representation: images of illness from madness to AIDS. Ithaca, NY: Cornell University Press, 1994.

GREEN, R.A. The hurdy-gurdy in eighteenth-century France. Bloomington, Indiana: Indiana University Press, 1995.

HAMILTON, R.H.; PASCUAL-LEONE, A.; SCHLAUG, G. Absolute pitch in blind musicians: auditory and vestibular systems. Neuroreport, London, v. 15, n. 5, p. 803-806, 2004.

KIDULA, J. Polishing the luster of the stars: music professionalism made workable in Kenya. Ethnomusicology, Bloomingoton, v. 44, n. 3, p. 408-428, 2000.

KUBIK, G. Xylophone playing in Southern Uganda. The Journal of the Royal Anthropological Institute of Great Britain and Ireland, London, v. 94, n. 2, p. 138-159, 1964.

LANG, H.G.; MEATH-LANG, B. A biographical dictionary: deaf persons in the Arts and Sciences. London: Greenwood Press, 1995.

LINTON, S. Claiming disability: knowledge and identity. New York: New York University Press, 1998.

OTTENBERG, S. Seeing with music: the lives of three blind African Musicians. Washington, DC: University of Washington Press, 1996.

PRING, L.; OCKELFORD, A. Children with septo-optic dysplasia - musical interests, abilities and provision: the results of a parental survey. British Journal of Visual Impairment, Birmingham, UK, v. 23, n. 2, p. 58-66, 2005.

ROSS, D.A.; OLSON, I.R.; GORE, J.C. Cortical plasticity in an early blind musician: an fMRl study. Magnetic Resonance Imaging, New York, v. 21, n. 7, p. 821-828, 2003. 
Músicos cegos ou cegos músicos...

RUSSELL, J. M. Sennacherib's palace without rival at Nineveh. Chicago: University of Chicago Press, 1991.

TSUGE, G. Symbolic Techniques in Japanese Koto-Kumiuta. Asian Music, University of Texas, v. 12, n. 2, p. 109-132, 1981. 